\title{
Early Results of Goniotomy with the Kahook Dual Blade, a Novel Device for the Treatment of Glaucoma
}

This article was published in the following Dove Press journal:

Clinical Ophthalmology

\author{
Helen L Kornmann' \\ Ronald L Fellman' \\ William J Feuer ${ }^{2}$ \\ Michelle R Butler' \\ David G Godfrey' \\ Oluwatosin U Smith (D) \\ Matthew E Emanuel' \\ Davinder S Grover' \\ 'Glaucoma Associates of Texas, Dallas, \\ Texas, USA; ${ }^{2}$ Department of \\ Ophthalmology, Bascom Palmer Eye \\ Institute, Miami, Florida, USA
}

Purpose: To report the outcomes of patients who underwent goniotomy with the Kahook Dual Blade (KDB) either as a standalone procedure or in combination with cataract extraction.

Patients and methods: This retrospective chart review included 111 eyes of 90 patients who underwent KDB goniotomy from January to November 2016 at Glaucoma Associates of Texas. KDB goniotomy was combined with cataract surgery in 100 eyes. The main outcome measures were postoperative intraocular pressure (IOP) and number of IOP lowering medications.

Results: Preoperatively, mean IOP was $17.1 \pm 4.7 \mathrm{mmHg}$ (range $8-34 \mathrm{mmHg}$ ) and mean number of IOP lowering medications was $2.4 \pm 1.3$ (range 0-6). Postoperatively, mean IOP was $14.9 \mathrm{mmHg}, 13.9 \mathrm{mmHg}, 14.1 \mathrm{mmHg}, 14.4 \mathrm{mmHg}$, and $14.7 \mathrm{mmHg}$ at 1, 3, 6, 9, and 12 months follow-up, respectively (all $\mathrm{p}<0.004$ ). Mean numbers of IOP lowering medications were $0.8,1.0,1.0,1.0$, and 1.6 at $1,3,6,9$, and 12 months follow-up, respectively (all $\mathrm{p}<0.001$ ). The cumulative reoperation rates for uncontrolled IOP after KDB were $0 \%, 1.0 \%$, $2.1 \%$, and $4.6 \%$ at $3,6,9$, and 12 months, respectively. Eyes with a preoperative IOP $>21$ $\mathrm{mmHg}$ were significantly more likely to undergo reoperation $(\mathrm{p}=0.038$, log-rank test). There were no serious complications at any time point in the follow-up period.

Conclusion: The Kahook Dual Blade results in a reduction in IOP and use of glaucoma medications after one year of follow-up. Further prospective studies are needed to fully characterize safety and efficacy.

Keywords: goniotomy, kahook dual blade, minimally invasive
Correspondence: Helen L Kornmann Glaucoma Associates of Texas, 10740 N. Central Expy, Suite 300, Dallas, TX 7523I, USA

Tel $+1214360-0000$

Fax + I2I 4 360-0083

Email hkornmann@glaucomaassociates. com

\section{Introduction}

Glaucoma is a leading cause of irreversible blindness, with estimates projecting nearly 112 million people affected worldwide by the year 2040. ${ }^{1}$ Elevated intraocular pressure (IOP) is a significant risk factor for disease progression. Controlling IOP is the mainstay of glaucoma therapy, and when medical therapy inadequately lowers IOP, surgical intervention is often indicated. While traditional glaucoma surgeries such as trabeculectomy and aqueous shunt implantation result in substantial IOP reductions, they are also associated with significant risks. ${ }^{2,3}$ Recently, minimally invasive glaucoma surgeries (MIGS) have gained in popularity due to their favorable safety profile, ability to be combined with cataract surgery, and the reduction or elimination of adjunctive glaucoma medications. This is especially relevant for patients who experience difficulty with medication adherence or those with significant ocular surface disease from topical glaucoma medications.

It is currently thought that a major component of IOP dysregulation is caused by obstruction of aqueous outflow at the level of the trabecular meshwork (TM), ${ }^{4,5}$ and by 
removing the TM, the natural outflow pathways may possibly be restored. This can be achieved in a variety of ways, and several of the recent MIGS procedures have targeted the TM by either bypassing or removing the tissue altogether. Goniotomy was first described by Otto Barkan in $1938^{6}$ and has been used as a surgical treatment for pediatric glaucoma. However, traditional goniotomy has not had great long-term success in adults, which may be due, in part, to re-closure of the trabecular leaflets, incomplete removal of the TM, and/or scarring and membrane formation across the TM leaflets, leading to elevated IOP. A more thorough removal of the TM and inner wall of Schlemm's canal may allow for patency of the opening to Schlemm's canal and potentially result in a sustained reduction in IOP.

The Kahook Dual Blade (KDB, New World Medical, Rancho Cucamonga, CA) is a novel single-use ophthalmic knife with two parallel blades designed to remove a strip of TM tissue and the inner wall of Schlemm's canal. The procedure can be performed alone or in combination with other procedures through a clear corneal incision. Preclinical studies have shown that the dual blade achieves a more complete removal of TM tissue without injuring surrounding tissues than either goniotomy with a microvitreoretinal blade or the trabectome. ${ }^{7}$ There are, however, limited clinical studies evaluating the safety and efficacy of this treatment. The goal of the current study is to report the outcomes of patients undergoing KDB goniotomy, either as a standalone procedure or in combination with cataract surgery, with up to one year of follow-up.

\section{Materials and Methods}

A retrospective chart review was performed for all patients who underwent a KDB goniotomy at Glaucoma Associates of Texas from January to November 2016. The study protocol was reviewed by the Sterling IRB ethics board, which granted a waiver of consent for this retrospective analysis of existing health records. The study followed the tenets of the Declaration of Helsinki, and patient data were collected and maintained with confidentiality.

\section{Surgical Procedure}

The Kahook dual blade is a single-use ophthalmic knife that is inserted into the eye via a clear corneal incision. The distal end of the stainless steel body consists of a pointed tip that pierces the TM and facilitates entry of the blade into Schlemm's canal. A ramp proximal to the tip lifts and stretches the TM to theoretically enable smooth cutting of the TM with the parallel dual blades as the device is moved circumferentially along the canal, exposing the outer wall of Schlemm's canal. The strip of TM can often be removed from the eye with intraocular forceps or aspirated from the eye.

Dual blade goniotomy was performed either as an isolated procedure or in combination with cataract surgery by seven glaucoma-trained surgeons (MRB, DGG, MEE, RLF, OS, DSG, HLK). For the dual blade procedure, a clear corneal incision was made in the temporal cornea, and the anterior chamber was filled with a cohesive viscoelastic (sodium hyaluronate). The head was then rotated 30 to 45 degrees away from the surgeon, and the microscope tilted 30 to 45 degrees toward the surgeon. A direct goniolens was then used to visualize the nasal angle structures. Additional viscoelastic was injected into the eye if needed to improve visualization. The dual blade was then inserted into the anterior chamber, and the tip of the blade used to pierce the TM so that the footplate of the blade could be seated within Schlemm's canal. The device was then advanced along Schlemm's canal in the direction of the pointed tip, either in the clockwise or counterclockwise direction. After adequate removal of the TM, the blade was rotated 180 degrees and inserted back into Schlemm's canal at the point of original insertion, and advanced in the opposite direction. Following treatment, the back wall of Schlemm's canal could be visualized as an opaque white line. The dual blade was then removed from the anterior chamber, and the freefloating strip of TM was removed with microsurgical forceps when present and possible. The head and microscope were then rotated back to their original position and the viscoelastic and any blood reflux was irrigated out of the eye. When this procedure was combined with cataract surgery, the goniotomy was usually performed prior to cataract surgery; however, this varied based on surgeon and patient.

The patients were followed postoperatively as per the surgeon's discretion. Typically, patients were seen at postoperative day 1 , week 1 , and with subsequent visits determined based on the degree of inflammation and/or other concomitant procedures performed. Patients were typically placed on a topical fourth-generation fluoroquinolone antibiotic and topical steroid, which was tapered according to the surgeon's clinical judgment. The need for reinstating glaucoma medications and the choice of medication used was also at the discretion of the surgeon.

\section{Statistical Analysis}

Interval level data were summarized with means and standard deviations and di- or polychotomous data were 
summarized with proportions. Means were compared between follow-up times with the paired $t$-test and between groups with the two-sample $t$-test. Cumulative proportions of eyes reoperated were calculated using Kaplan-Meier methods and were compared between groups with the log-rank test. Eyes included in the Kaplan-Meier plots which had not undergone reoperation were censored at the time of their last follow-up. Eyes having undergone prior reoperation were censored from the intraocular pressure summary statistics for each visit.

\section{Results}

\section{Characteristics of Study Patients}

A total of 111 eyes of 90 patients underwent surgery. The mean age was 70 years (range 23 to 94 years). The number of male patients was $48(53 \%)$ and the majority of patients were Caucasian ( $\mathrm{n}=52,58 \%$ ) (See Table 1 for baseline characteristics). Primary open-angle glaucoma was the most common diagnosis $(n=66,60 \%)$. The severity of glaucoma varied from mild to severe with an average mean deviation on visual field testing of $-6.4 \pm 5.8 \mathrm{~dB}$ (range: -24.5 to $0.4 \mathrm{~dB}$ ). Surgery was combined with cataract extraction in $100(90 \%)$ eyes. Follow-up ranged from 1 to 15 months. The median (interquartile range) of follow-up was 12 (IQR 3.6) months. Overall, 72 of 111 eyes were evaluated at 12 months. The remaining 39 eyes were not seen at 12 months due to follow-up time less than 12 months at the time of data collection ( $\mathrm{n}=34)$, the need for additional glaucoma surgery $(n=4)$, or loss to follow-up $(n=1)$.

\section{Effect of KDB on Postoperative IOP and Pressure Lowering Medication Use}

Mean IOP decreased from $17.1 \pm 4.7 \mathrm{mmHg}$ at baseline to $14.9 \pm 4.6 \mathrm{mmHg}, 13.9 \pm 3.6 \mathrm{mmHg}, 14.1 \pm 3.8 \mathrm{mmHg}$, $14.4 \pm 2.9 \mathrm{mmHg}$, and $14.7 \pm 3.5 \mathrm{mmHg}$ at $1,3,6,9$, and 12 months follow-up, respectively (all $\mathrm{p}<0.004$ ) (Figure 1 ). The efficacy of KBD on IOP lowering by follow-up visit and preoperative IOP are detailed in Table 2. From postoperative month 1 through month 12, the percentage of eyes with IOP lowered by $20 \%$ of the preoperative measurement ranged from $32 \%$ to $42 \%$. The higher the preoperative IOP, the greater the IOP lowering effect of KDB on these eyes. In eyes with a preoperative IOP $>21 \mathrm{mmHg}$, mean IOP decreased by $8.6 \pm 4.7 \mathrm{mmHg}$ at 12 months, compared to eyes with a preoperative IOP $<14 \mathrm{mmHg}$, which demonstrated a $1.8 \pm 3.5 \mathrm{mmHg}$ reduction in IOP at 12 months. As
Table I Baseline Characteristics

\begin{tabular}{|c|c|}
\hline \multicolumn{2}{|l|}{ Patients N (\%) } \\
\hline Male Gender & $48(53 \%)$ \\
\hline \multicolumn{2}{|l|}{ Self-Identified Ethnicity } \\
\hline African American & $18(20 \%)$ \\
\hline Asian & $3(3 \%)$ \\
\hline Hispanic & $6(7 \%)$ \\
\hline Caucasian & $52(58 \%)$ \\
\hline Multi-ethnic & $5(6 \%)$ \\
\hline Native American & $3(3 \%)$ \\
\hline Declined to answer & $3(3 \%)$ \\
\hline \multicolumn{2}{|l|}{ Eyes } \\
\hline \multicolumn{2}{|l|}{ Glaucoma Diagnosis } \\
\hline POAG & $66(60 \%)$ \\
\hline CNAG & $12(11 \%)$ \\
\hline Pseudoexfoliation & $4(4 \%)$ \\
\hline PDG & $5(5 \%)$ \\
\hline LTG & $8(7 \%)$ \\
\hline Other & $16(14 \%)$ \\
\hline \multicolumn{2}{|l|}{ Preoperative IOP } \\
\hline$<14 \mathrm{mmHg}$ & $26(23 \%)$ \\
\hline $\mid 4-<18 \mathrm{mmHg} 40$ (36\%) & \\
\hline I8-2| mmHg 30 (27\%) & \\
\hline$>21 \mathrm{mmHg}$ & $15(14 \%)$ \\
\hline \multicolumn{2}{|l|}{ Preoperative Number of Medications } \\
\hline$<2$ & $33(30 \%)$ \\
\hline 2 & $31(28 \%)$ \\
\hline 3 & $24(22 \%)$ \\
\hline $4-6$ & $23(21 \%)$ \\
\hline \multicolumn{2}{|l|}{ Preoperative Visual Acuity } \\
\hline $20 / 20-20 / 40$ & 87 (78\%) \\
\hline $20 / 50-20 / 80$ & $16(14 \%)$ \\
\hline $20 / 100-20 / 400$ & $6(5 \%)$ \\
\hline CF, HM & $2(2 \%)$ \\
\hline Eye Undergoing Surgery, Right & $62(56 \%)$ \\
\hline Prior CE & $4(4 \%)$ \\
\hline Combined with CE & $100(90 \%)$ \\
\hline
\end{tabular}

Abbreviations: $\mathrm{CE}$, cataract extraction; $\mathrm{CF}$, counting fingers; $\mathrm{CNAG}$, chronic narrow angle glaucoma; HM, hand motion; IOP, intraocular pressure; LTG, low tension glaucoma; PDG, pigment dispersion glaucoma; POAG, primary open-angle glaucoma.

expected, the percentage of eyes with a $20 \%$ lowering increased with preoperative pressure.

Medication use also decreased after KDB goniotomy. Mean medication use preoperatively and at follow-up are displayed in Figure 2. The average number of medications used preoperatively was $2.4 \pm 1.3$ (range 0 to 6), and 18 patients were also using oral medications to control IOP. Medication use decreased to $0.8 \pm 1.1,1.0 \pm 1.2,1.0 \pm 1.4$, 


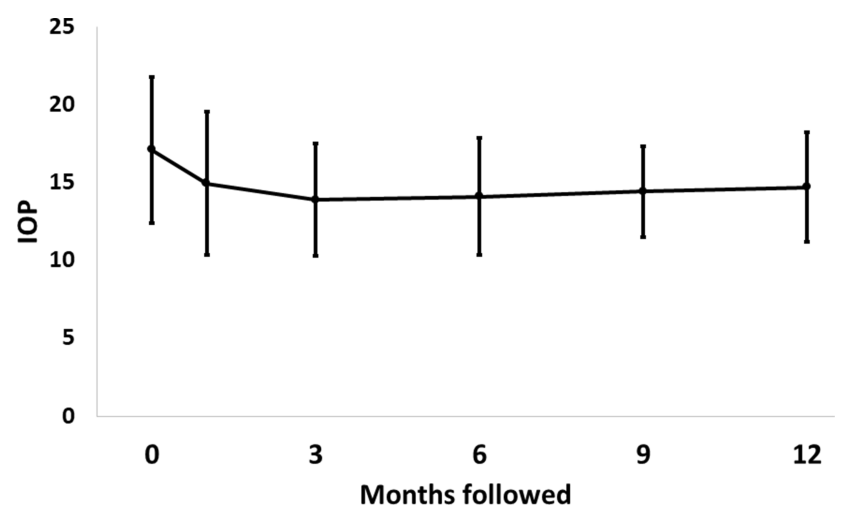

Figure I Intraocular pressure (IOP, $\mathrm{mmHg}$ ) at baseline and at follow-up. There is an early drop in IOP that remains relatively stable during the first 12 months of follow-up. (Error bar = I standard deviation).

$1.0 \pm 1.3$, and $1.1 \pm 1.3$ at $1,3,6,9$, and 12 months followup, respectively (all $\mathrm{p}<0.001$ ). Table 3 details medication use following KDB goniotomy by follow-up visit and preoperative number of medications used. From postoperative month 1 through month 12 , the percentage of eyes with a reduction in the number of medications required ranged from $75 \%$ to $90 \%$. Similar to IOP, the percentage of eyes with postoperative medication reduction increased with the number of medications used preoperatively. At all follow- up visits, more than $80 \%$ of the eyes experienced either a $20 \%$ lowering of IOP or reduction in the number of medications.

\section{Reoperation for IOP Control}

Four eyes receiving KBD underwent reoperation to surgically lower IOP. Cumulative reoperation rates were $0 \%$, $1.0 \%, 2.1 \%$, and $4.6 \%$ at $3,6,9$, and 12 months, respectively. Figure 3 displays Kaplan-Meier cumulative failure rates by preoperative IOP group. Eyes with preoperative IOP $>21$ $\mathrm{mmHg}$ were statistically significantly more likely to undergo reoperation than those with an IOP between $18 \mathrm{mmHg}$ and $21 \mathrm{mmHg}(\mathrm{p}=0.038$, log-rank test $)$ and those with a preoperative IOP $<18 \mathrm{mmHg}(\mathrm{p}=0.005)$. At 12 months of follow-up, $28.7 \%$ of the eyes with a preoperative IOP $>21$ $\mathrm{mmHg}, 5.3 \%$ of the eyes with a preoperative IOP $18-21$ $\mathrm{mmHg}$, and zero percent of eyes with a preoperative IOP $<18 \mathrm{mmHg}$ required reoperation to lower IOP.

\section{Complications}

Complications (apart from reoperation to control IOP) were assessed on 115 eyes of 91 patients and were found infrequently. A single intraoperative complication of

Table 2 KDB Efficacy on IOP and Medication Use by Preoperative IOP Levels and Follow-Up Visit

\begin{tabular}{|c|c|c|c|c|c|c|}
\hline Preoperative IOP Group & Measure of Efficacy & POM I & POM 3 & POM 6 & POM 9 & POM 12 \\
\hline$<14 \mathrm{mmHg}$ & $\begin{array}{l}\text { Number }(\mathrm{N}) \\
\text { Mean (SD) IOP lowering } \\
\mathrm{N}(\%) \text { IOP lowered } 20 \% \\
\mathrm{~N}(\%) \text { IOP lowered } 20 \% \text { or decrease in number of meds }\end{array}$ & $\begin{array}{l}26 \\
-2.0(4.2) \\
3(12 \%) \\
22(85 \%)\end{array}$ & $\begin{array}{l}24 \\
-0.4(2.9) \\
3(13 \%) \\
20(83 \%)\end{array}$ & $\begin{array}{l}18 \\
-1.3(2.9) \\
2(11 \%) \\
15(83 \%)\end{array}$ & $\begin{array}{l}23 \\
-2.2(2.6) \\
0 \\
18(78 \%)\end{array}$ & $\begin{array}{l}21 \\
-1.8(3.5) \\
2(10 \%) \\
17(81 \%)\end{array}$ \\
\hline $14-17.9 \mathrm{mmHg}$ & $\begin{array}{l}\text { Number }(\mathrm{N}) \\
\text { Mean (SD) IOP lowering } \\
\mathrm{N}(\%) \text { IOP lowered } 20 \% \\
\mathrm{~N}(\%) \text { IOP lowered } 20 \% \text { or decrease in number of meds }\end{array}$ & $\begin{array}{l}38 \\
1.3(4.6) \\
10(26 \%) \\
33(87 \%)\end{array}$ & $\begin{array}{l}35 \\
2.2(3.0) \\
16(46 \%) \\
31(89 \%)\end{array}$ & $\begin{array}{l}32 \\
2.1(2.8) \\
13(41 \%) \\
29(91 \%)\end{array}$ & $\begin{array}{l}22 \\
1.7(2.7) \\
7(32 \%) \\
20(91 \%)\end{array}$ & $\begin{array}{l}26 \\
1.8(3.0) \\
9(35 \%) \\
21(81 \%)\end{array}$ \\
\hline$|8-2|$ & Number $(\mathrm{N})$ & 30 & 28 & 20 & 23 & 18 \\
\hline $\mathrm{mmHg}$ & $\begin{array}{l}\text { Mean (SD) IOP lowering } \\
N(\%) \text { IOP lowered } 20 \% \\
N(\%) \text { IOP lowered } 20 \% \text { or decrease in number of meds }\end{array}$ & $\begin{array}{l}4.0(3.7) \\
14(48 \%) \\
24(80 \%)\end{array}$ & $\begin{array}{l}4.6(4.1) \\
14(50 \%) \\
24(86 \%)\end{array}$ & $\begin{array}{l}4.4(4.3) \\
10(50 \%) \\
16(80 \%)\end{array}$ & $\begin{array}{l}3.9(3.6) \\
12(52 \%) \\
20(87 \%)\end{array}$ & $\begin{array}{l}2.4(3.6) \\
7(39 \%) \\
13(72 \%)\end{array}$ \\
\hline$>21 \mathrm{mmHg}$ & $\begin{array}{l}\text { Number }(\mathrm{N}) \\
\text { Mean (SD) IOP lowering } \\
\mathrm{N}(\%) \text { IOP lowered } 20 \% \\
\mathrm{~N}(\%) \text { IOP lowered } 20 \% \text { or decrease in number of meds }\end{array}$ & $\begin{array}{l}15 \\
8.1(8.8) \\
12(80 \%) \\
15(100 \%)\end{array}$ & $\begin{array}{l}15 \\
9.7(7.2) \\
10(67 \%) \\
14(93 \%)\end{array}$ & $\begin{array}{l}9 \\
5.9(5.1) \\
5(56 \%) \\
7(78 \%)\end{array}$ & $\begin{array}{l}4 \\
8.6(1.1) \\
4(100 \%) \\
4(100 \%)\end{array}$ & $\begin{array}{l}7 \\
8.6(4.7) \\
6(86 \%) \\
7(100 \%)\end{array}$ \\
\hline Total & $\begin{array}{l}\text { Number }(\mathrm{N}) \\
\text { Mean (SD) IOP lowering } \\
\mathrm{N}(\%) \text { IOP lowered } 20 \% \\
\mathrm{~N}(\%) \text { IOP lowered } 20 \% \text { or decrease in number of meds }\end{array}$ & $\begin{array}{l}109 \\
2.2(6.0) \\
39(36 \%) \\
94(86 \%)\end{array}$ & $\begin{array}{l}102 \\
3.4(5.2) \\
43(42 \%) \\
89(87 \%)\end{array}$ & $\begin{array}{l}79 \\
2.4(4.2) \\
30(38 \%) \\
67(85 \%)\end{array}$ & $\begin{array}{l}72 \\
1.5(4.2) \\
23(32 \%) \\
62(86 \%)\end{array}$ & $\begin{array}{l}72 \\
1.6(4.5) \\
24(33 \%) \\
58(8 \mid \%)\end{array}$ \\
\hline
\end{tabular}

Abbreviations: IOP, intraocular pressure; KDB, Kahook Dual Blade; POM, postoperative month; SD, standard deviation. 


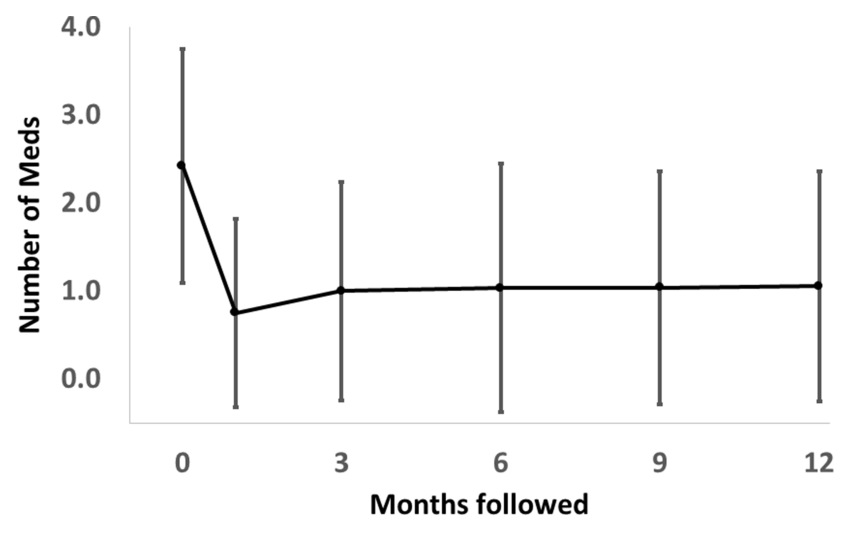

Figure 2 Glaucoma medication use at baseline and at follow-up. There is an early and sustained decrease in medication use after Kahook dual blade goniotomy. (Error bar = I standard deviation).

a cyclodialysis cleft was repaired during the time of surgery and was not seen postoperatively. The most common postoperative complication was hyphema, which occurred in 4 patients within the first postoperative week and resolved by postoperative month 1 in all but one patient.
This patient underwent complex cataract extraction, goniosynechiolysis, and KDB and was also on chronic anticoagulant therapy; hyphema was no longer noted after 3 months.

\section{Discussion}

The current study demonstrates that goniotomy with the $\mathrm{KDB}$, either alone or in combination with cataract extraction, results in a reasonable reduction in IOP and glaucoma medication use in various types and stages of glaucoma. After one year of follow-up, among those eyes not reoperated, IOP decreased by a mean of 1.6 $\mathrm{mmHg}$ ( $10 \%$ from baseline) and medication use also decreased by an average of 1.2 (53\% from baseline), with $75 \%$ of the patients having at least one or more reduction in medication. The severity of glaucoma included in this study ranged from mild to severe, and surgery effectively lowered IOP in both open- and closedangle glaucomas. The safety profile of this procedure was

Table 3 KDB Efficacy on IOP and Medication Use by Preoperative Number of Medications and Follow-Up Visit

\begin{tabular}{|c|c|c|c|c|c|c|}
\hline $\begin{array}{l}\text { Preoperative } \\
\text { Number of } \\
\text { Medications }\end{array}$ & Measure of Efficacy & POM I & POM 3 & POM 6 & POM 9 & POM 12 \\
\hline 0 or 1 & $\begin{array}{l}\text { Number }(N) \\
\text { Mean (SD) meds decreased } \\
N(\%) \geq I \text { fewer meds } \\
N(\%) \text { IOP lowered } 20 \% \text { or } \\
\text { decrease in number of meds }\end{array}$ & $\begin{array}{l}32 \\
0.6(0.9) \\
24(75 \%) \\
26(81 \%)\end{array}$ & $\begin{array}{l}28 \\
0.6(0.9) \\
22(79 \%) \\
24(86 \%)\end{array}$ & $\begin{array}{l}24 \\
0.9(0.4) \\
22(92 \%) \\
22(92 \%)\end{array}$ & $\begin{array}{l}24 \\
0.8(0.5) \\
19(79 \%) \\
20(83 \%)\end{array}$ & $\begin{array}{l}22 \\
0.6(0.6) \\
15(68 \%) \\
16(73 \%)\end{array}$ \\
\hline 2 & $\begin{array}{l}\text { Number }(N) \\
\text { Mean (SD) meds decreased } \\
N(\%) \geq I \text { fewer meds } \\
N(\%) \text { IOP lowered } 20 \% \text { or } \\
\text { decrease in number of meds }\end{array}$ & $\begin{array}{l}31 \\
1.3(0.9) \\
23(74 \%) \\
25(81 \%)\end{array}$ & $\begin{array}{l}29 \\
1.2(1.1) \\
22(76 \%) \\
25(86 \%)\end{array}$ & $\begin{array}{l}22 \\
1.0(1.3) \\
15(68 \%) \\
17(77 \%)\end{array}$ & $\begin{array}{l}22 \\
1.1(1.3) \\
16(73 \%) \\
18(82 \%)\end{array}$ & $\begin{array}{l}24 \\
0.9(1.2) \\
16(67 \%) \\
19(79 \%)\end{array}$ \\
\hline 3 & $\begin{array}{l}\text { Number }(N) \\
\text { Mean (SD) meds decreased } \\
N(\%) \geq I \text { fewer meds } \\
N(\%) \text { IOP lowered } 20 \% \text { or } \\
\text { decrease in number of meds }\end{array}$ & $\begin{array}{l}24 \\
2.2(1.0) \\
23(96 \%) \\
23(96 \%)\end{array}$ & $\begin{array}{l}22 \\
1.8(1.2) \\
19(86 \%) \\
20(91 \%)\end{array}$ & $\begin{array}{l}17 \\
1.9(1.4) \\
12(71 \%) \\
14(82 \%)\end{array}$ & $\begin{array}{l}16 \\
1.6(1.2) \\
13(81 \%) \\
14(88 \%)\end{array}$ & $\begin{array}{l}14 \\
2(1.2) \\
12(86 \%) \\
12(86 \%)\end{array}$ \\
\hline $4-6$ & $\begin{array}{l}\text { Number }(N) \\
\text { Mean (SD) meds decreased } \\
N(\%) \geq I \text { fewer meds } \\
N(\%) \text { IOP lowered } 20 \% \text { or } \\
\text { decrease in number of meds }\end{array}$ & $\begin{array}{l}22 \\
3.1(1.5) \\
20(91 \%) \\
20(9 \mid \%)\end{array}$ & $\begin{array}{l}23 \\
2.5(1.5) \\
20(87 \%) \\
20(87 \%)\end{array}$ & $\begin{array}{l}16 \\
1.9(1.7) \\
13(81 \%) \\
14(88 \%)\end{array}$ & $\begin{array}{l}10 \\
1.5(1.4) \\
13(81 \%) \\
10(100 \%)\end{array}$ & $\begin{array}{l}12 \\
1.9(1.7) \\
11(92 \%) \\
11(92 \%)\end{array}$ \\
\hline Total & $\begin{array}{l}\text { Number }(N) \\
\text { Mean (SD) meds decreased } \\
N(\%) \geq I \text { fewer meds } \\
N(\%) \text { IOP lowered } 20 \% \text { or } \\
\text { decrease in number of meds }\end{array}$ & $\begin{array}{l}109 \\
1.7(1.4) \\
90(83 \%) \\
94(86 \%)\end{array}$ & $\begin{array}{l}102 \\
1.5(1.3) \\
83(81 \%) \\
89(87 \%)\end{array}$ & $\begin{array}{l}79 \\
1.3(1.3) \\
62(79 \%) \\
67(85 \%)\end{array}$ & $\begin{array}{l}72 \\
1.2(1.1) \\
9(90 \%) \\
62(86 \%)\end{array}$ & $\begin{array}{l}72 \\
1.2(1.3) \\
54(75 \%) \\
11(92 \%)\end{array}$ \\
\hline
\end{tabular}

Abbreviations: IOP, intraocular pressure; KDB, Kahook Dual Blade; POM, postoperative month; SD, standard deviation. 


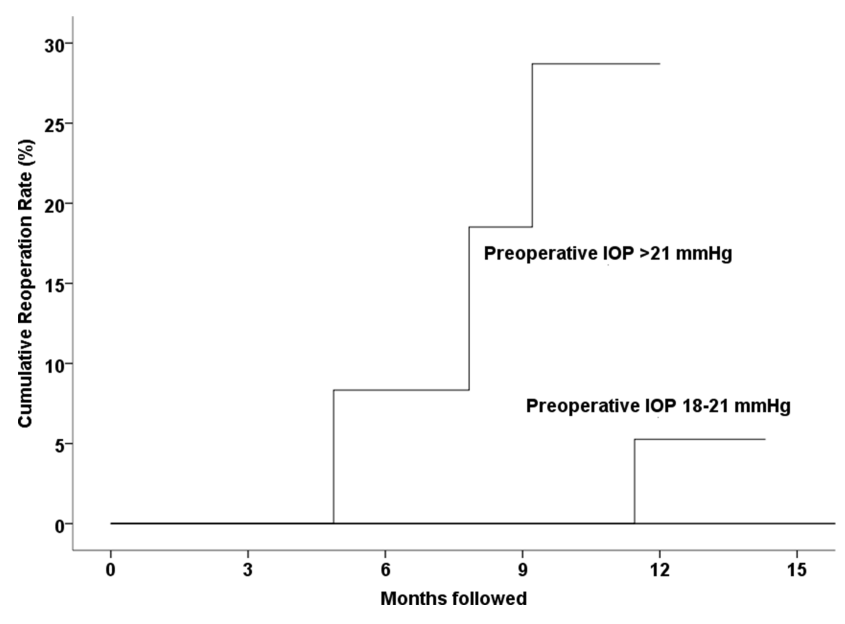

Figure 3 Kaplan-Meier cumulative failure rates by preoperative intraocular pressure (IOP) group. Eyes with preoperative IOP $>21 \mathrm{mmHg}$ were statistically significantly more likely to undergo reoperation than those with IOP between 18 $\mathrm{mmHg}$ and $21 \mathrm{mmHg}(\mathrm{P}=0.038$, log-rank test $)$ and those with preoperative IOP $<18 \mathrm{mmHg}(P=0.005)$.

also favorable, with the most common complication being self-limited hyphema. This study also indicates that while the most robust IOP reduction was achieved in those with higher IOPs, even in eyes with well-controlled IOP, medication use was decreased.

The TM is a logical target for MIGS procedures because it is the area of greatest resistance to aqueous outflow and it is easy to access. Goniotomy by means of direct incision with a microvitreoretinal blade, ablation with the trabectome, or removal of a strip of TM with the KDB aims to re-establish and enhance flow through the conventional outflow pathway. Unlike traditional goniotomy, which commonly results in leaflets of residual $\mathrm{TM}$ especially in adults, the KDB removes a complete strip of TM and may thus result in improved IOP control.

The results of this study seem to be comparable to those of the trabectome. Bussel et al evaluated the outcomes of trabectome following failed trabeculectomy after one year of follow-up. ${ }^{8}$ After standalone trabectome, mean IOP decreased from $23.7 \mathrm{mmHg}$ at baseline to $16.2 \mathrm{mmHg}$ ( $28 \%$ reduction, $\mathrm{p}<0.01$ ) and mean medications decreased from 2.8 to $2.0(\mathrm{p}<0.01)$. Combined phacoemulsificationtrabectome resulted in an IOP decrease from $20.0 \mathrm{mmHg}$ to $15.6 \mathrm{mmHg}$ ( $19 \%$ reduction, $\mathrm{p}=0.11)$, while medications decreased from 2.5 to $1.6(\mathrm{p}=0.24)$. Okeke et al reported similar outcomes in phakic patients from the Trabectome Study Group undergoing trabectome alone or in combination with cataract surgery. ${ }^{9}$ After 12 months of follow-up, the IOP for the trabectome only group was reduced from $21.0 \mathrm{mmHg}$ to $15.8 \mathrm{mmHg}(\mathrm{p}<0.01)$ and $26.5 \mathrm{mmHg}$ to $16.3 \mathrm{mmHg}$
( $p<0.01)$ in the combined surgery group. Additionally, both groups decreased medication use by one at 12 months. Ahuja et al evaluated outcomes of trabectome in open-angle glaucomas using two different success criteria. ${ }^{10}$ The first required a postoperative IOP $\leq 21 \mathrm{mmHg}$ or $\geq 20 \%$ reduction in IOP, and a second stricter criterion required an IOP $\leq 18$ $\mathrm{mmHg}$ and $\geq 20 \%$ reduction in IOP. Success rates with the stricter criterion were low at $22 \%$ after 24 months, suggesting that trabectome is more appropriate for individuals who do not require a very low IOP. The authors have not seen this level of failure with the KDB, but longer-term studies are required. A recent meta-analysis found that on average, trabectome lowers IOP by approximately $31 \%$ to a final IOP near $15 \mathrm{mmHg}$ while decreasing the number of medications by less than one, with a low rate of serious complications. ${ }^{11}$

Studies evaluating the safety and efficacy of the Kahook dual blade are limited. The earliest clinical study by Greenwood et al reported the six-month outcomes of patients who underwent combined cataract extraction and KDB goniotomy. ${ }^{12}$ A total of 71 eyes were included in the study, with the majority of patients diagnosed with primary openangle glaucoma (70\%). Mean IOP decreased from 17.4 $\mathrm{mmHg}$ at baseline to $12.8 \mathrm{mmHg}(\mathrm{p}<0.001)$, and glaucoma medication use also decreased from 1.6 to $0.9(\mathrm{p}=0.005)$. Intraoperative blood reflux was the most commonly observed adverse event (39.4\%). Surgeons reported that in $98 \%$ of the cases, the use of the KDB was straightforward and efficient.

More recently, Sieck et al reported the outcomes of 197 eyes that underwent combined cataract extraction and KDB goniotomy or KDB as a standalone procedure. ${ }^{13}$ Success was defined as an IOP reduction of at least $20 \%$ from baseline and/or a reduction of at least one glaucoma medication. Unlike the patients in the current study, all patients were started on pilocarpine (1\%) solution 4 times daily during the first postoperative month, in addition to the standard topical antibiotic and steroid regimen. After 12 months, the success rate was $71.8 \%$ in the combined group and $68.8 \%$ in the KDB alone group. Success was also stratified according to severity of glaucoma, with KDB being more effective in those with less severe disease (success rate of $77.1 \%$ in mild, $68.1 \%$ in moderate, $60.0 \%$ in severe, and $77.8 \%$ in indeterminate glaucoma). Similar to our study, complications were mild, with hyphema (17.3\%) being the most common. Four patients required additional surgery for uncontrolled IOP within the first postoperative month.

Our study highlights a key factor in evaluating MIGS outcomes. While traditional glaucoma surgeries such as 
trabeculectomy and tube shunts are typically reserved for more advanced cases, most MIGS procedures are used in mild stages of disease with the aim of moderately lowering IOP as well as decreasing the dependence on glaucoma medications. The current study comprised patients at various stages of glaucoma, including those with advanced disease. Grover et al previously demonstrated that proportions of success following gonioscopy-assisted transluminal trabeculotomy (GATT) in primary open-angle glaucoma patients was heavily dependent upon stage of disease, with high proportions of failure occurring in eyes with a mean deviation worse than $-15 \mathrm{~dB}$. Alternatively, relatively high proportions of success were reported in eyes with a mean deviation better than $-15 \mathrm{~dB} .{ }^{14}$ The effect of KDB goniotomy in patients with severe or refractory glaucoma was recently reported by Salinas et al. ${ }^{15} \mathrm{In}$ this retrospective study, 53 eyes with severe or refractory glaucoma underwent KDB goniotomy as a standalone procedure. Twelve eyes had already undergone previous glaucoma surgery. Mean preoperative IOP was $18.4 \mathrm{mmHg}$ and mean number of IOP lowering medications was 2.6 . After 6 months of follow-up, $57.7 \%$ of the eyes achieved an IOP reduction of $\geq 20 \%$, and the proportion of patients with a decrease of at least 1 medication was $63.3 \%$. Overall, there was a $24 \%$ reduction in IOP and $36 \%$ reduction in number of medications. Unlike the findings from Grover et al, disease stage as measured by baseline mean deviation, pattern standard deviation, and retinal nerve fiber layer thickness were not significantly associated with failure.

Traditional definitions of success, as used in the Tube Versus Trabeculectomy study, Primary Tube Versus Trabeculectomy study, Ahmed Baerveldt Comparison study, and Ahmed Versus Baerveldt study, which required IOP lowering of greater than or equal to $20 \%$ and an IOP of less than $21 \mathrm{mmHg}$, do not seem pertinent when discussing MIGS in patients with mild/moderate stages of glaucoma. By these standards, the proportion of success from KBD goniotomy is relatively low. However, if one considers KDB goniotomy as a dual-purpose procedure that achieves a modest IOP reduction in conjunction with decreasing glaucoma medication burden, one can see from our study that these goals are accomplished at relatively reasonable rates.

This study adds to the growing body of literature evaluating the use of the KDB and supports the mounting evidence supporting canal-based procedures. The limitations of the study include its retrospective design, the variable amounts of treated TM that were not controlled for, and variations in the postoperative management. This study is also not powered to assess the effect of standalone KDB on IOP and medication reduction, as the majority of cases were combined with cataract surgery. As follow-up continues to grow, we will be able to better determine the long-term effects on IOP and medication use. In the future, a prospective, randomized control trial comparing KDB alone versus KDB combined with cataract surgery is needed to verify the results of this study.

The findings of this study are promising and demonstrate that goniotomy with the Kahook dual blade in combination with cataract surgery decreases IOP and glaucoma medication use up to one year after surgery. This study adds to our understanding of the safety and efficacy of KDB goniotomy for the treatment of glaucoma. Further prospective studies are needed to better characterize the long-term safety and efficacy of dual blade goniotomy, both as a standalone procedure or combined with other surgical procedures.

\section{Précis}

Goniotomy with the Kahook Dual Blade can be performed alone or in combination with cataract surgery and results in a decrease in intraocular pressure and glaucoma medication use.

\section{Disclosure}

DSG (consultant and speaker for New World Medical) and OS (consultant to New World Medical). The authors report no other conflicts of interest in this work.

\section{References}

1. Tham Y, Li X, Wong T, et al. Global prevalence of glaucoma and projections of glaucoma burden through 2040: a systematic review and meta-analysis. Ophthalmology. 2014;121:2081-2090. doi:10.1016/j. ophtha.2014.05.013

2. Gedde SJ, Schiffman JC, Feuer WJ, et al. Three-year follow-up of the tube versus trabeculectomy study. Am $J$ Ophthalmol. 2009;148:670-684. doi:10.1016/j.ajo.2009.06.018

3. Budenz DL, Feuer WJ, Barton K, et al. Postoperative complications in the Ahmed Baerveldt comparison study during five years of follow-up. $\mathrm{Am}$ J Ophthalmol. 2016;163(75-82):e73. doi:10.1016/j.ajo.2015.11.023

4. Grant WM. Clinical measurements of aqueous outflow. Am J Ophthalmol. 1951;34:1603-1605.

5. Tamm ER. The trabecular meshwork outflow pathways: structural and functional aspects. Exp Eye Res. 2009;88:648-655. doi:10.1016/j. exer.2009.02.007

6. Barkan O. Techniques of goniotomy. Arch Ophthalmol. 1938;19:217-221. doi:10.1001/archopht.1938.00850140059006

7. Seibold LK, Soohoo JR, Ammar DA, et al. Preclinical investigation of ab interno trabeculectomy using a novel dual-blade device. Am J Ophthalmol. 2013;155(524-529):e522. doi:10.1016/j.ajo.2012.09. 023 
8. Bussel II, Kaplowitz K, Schuman JS, et al. Outcomes of ab interno trabeculectomy with the trabectome by degree of angle opening. $\mathrm{Br}$ J Ophthalmol. 2015;99:914-919. doi:10.1136/bjophthalmol-2014-30 5577

9. Okeke CO, Miller-Ellis E, Rojas M, et al. Trabectome success factors. Medicine (Baltimore). 2017;96:e7061. doi:10.1097/MD.0 000000000007061

10. Ahuja Y, Ma Khin Pyi S, Malihi M, et al. Clinical results of ab interno trabeculotomy using the trabectome for open-angle glaucoma: the Mayo Clinic series in Rochester, Minnesota. Am J Ophthalmol. 2013;156(927-935):e922. doi:10.1016/j.ajo.2013.06.001

11. Kaplowitz K, Bussel II, Honkanen R, et al. Review and meta-analysis of ab-interno trabeculectomy outcomes. $\mathrm{Br} J$ Ophthalmol. 2016;100:594-600. doi:10.1136/bjophthalmol-2015-307131
12. Greenwood MD, Seibold LK, Radcliffe NM, et al. Goniotomy with a single-use dual blade: short-term results. J Cataract Refract Surg. 2017;43:1197-1201. doi:10.1016/j.jcrs.2017.06.046

13. Sieck EG, Epstein RS, Kennedy JB, et al. Outcomes of Kahook dual blade goniotomy with and without phacoemulsification cataract extraction. Ophthalmol Glaucoma. 2018;1:75-81. doi:10.1016/j. ogla.2018.06.006

14. Grover DS, Smith O, Fellman RL, et al. Gonioscopy-assisted transluminal trabeculotomy: an ab interno circumferential trabeculotomy: 24 months follow-up. J Glaucoma. 2018;27:393-401. doi:10.1097/ IJG.0000000000000956

15. Salinas L, Chaudhary A, Berdahl JP. et al. Goniotomy using the Kahook dual blade in severe and refractory glaucoma: six month outcomes. J Glaucoma;2018. 1. doi:10.1097/IJG.0000000000001019
Clinical Ophthalmology

\section{Publish your work in this journal}

Clinical Ophthalmology is an international, peer-reviewed journal covering all subspecialties within ophthalmology. Key topics include: Optometry; Visual science; Pharmacology and drug therapy in eye diseases; Basic Sciences; Primary and Secondary eye care; Patient Safety and Quality of Care Improvements. This journal is indexed on PubMed

\section{Dovepress}

Central and CAS, and is the official journal of The Society of Clinical Ophthalmology (SCO). The manuscript management system is completely online and includes a very quick and fair peer-review system, which is all easy to use. Visit http://www.dovepress.com/ testimonials.php to read real quotes from published authors. 